\title{
Sources of self-efficacy for motor learning in children: systematic literature review in clinical trials
}

\section{Fontes de autoeficácia para aprendizagem motora em crianças: revisão sistemática da literatura em ensaios clínicos}

\section{Sabrina Ferreira de Oliveira ${ }^{1,2}$ \\ (D) https://orcid.org/0000-0003-3784-4672 \\ Mariana Gurian Manzini² \\ (iD) https://orcid.org/0000-0002-9126-7514 \\ Mirela de Oliveira Figueiredo ${ }^{2}$ \\ (D) https://orcid.org/0000-0003-0101-0115 \\ Claudia Maria Simões Martinez $z^{2}$ \\ (D) https://orcid.org/0000-0002-8997-2767}

Abstract - This study aimed to verify the effects of intervention models on the motor activity of children elaborated from the self-efficacy theory. The systematic review of randomized controlled clinical trials with the PRISMA strategy was used. Sixteen studies were descriptively analyzed and revealed that knowledge based on the self-efficacy theory related to motor activity has been more frequently integrated into broad intervention programs in the school environment, collectively applied, stimulating aspects related to children's health and prevention of childhood obesity. Important results were obtained in the development of self-efficacy and motor activity stimulation; however, results are not conclusive regarding the mediation among these variables. Contributions for intervention programs are detailed in this manuscript, allowing the visualization of strategies to build a mastery context, favoring the establishment of an adequate concept of motor self-efficacy in children and the development of self-regulation skills. Key words: Motor activity; Self-efficacy; Systematic review.

Resumo - Este estudo teve por objetivo verificar os efeitos de modelos de intervençöes sobre a atividade motora de crianças, elaboradas a partir da teoria da autoeficácia. Utilizou-se a revisão sistemática de ensaios clínicos controlados randomizados empregando a estratégia PRISMA. Dezesseis estudos foram analisados descritivamente e revelaram que o conhecimento a partir da teoria da autoefcácia relacionada à atividade motora têm sido integrados com maior frequência em programas de intervenção em ambiente escolar, empregados de forma coletiva, estimulando aspectos relacionados à saúde das crianças e prevenção da obesidade infantil. Resultados importantes foram obtidos no desenvolvimento da autoeficácia e estímulo à atividade motora, mas não são conclusivos quanto à mediação entre essas variáveis. Contribuições acerca dos programas de intervenção são detalhadas nesse manuscrito permitindo visualizar estratégias de construção de um contexto de maestria, favorável ao estabelecimento de um adequado conceito de autoeficácia motora nas crianças e desenvolvimento de suas habilidades autorregulatórias.

Palavras-chave: Atividade motora; Autoeficácia; Revisão sistemática
1 "Triângulo Mineiro" Federal University. Uberaba, MG. Brazil.

2 Federal University of São Carlos. Postgraduate Program in Occupational Therapy. São Carlos, SP. Brazil.

Received: November 16, 2018 Accepted: October 10, 2019

How to cite this article Oliveira SF, Manzini MG, Figueiredo MO Martinez CMS. Sources of self-efficacy for motor learning in children: systematic literature review in clinical trials. Rev Bras Cineantropom Desempenho Hum 2020, 22:e60255. DOI: http://dx.doi. org/10.1590/1980-0037.2020v22e60255

Copyright: This work is licensed under a Creative Commons Attribution 4.0 International License. 


\section{INTRODUCTION}

Bandura ${ }^{1}$ defines self-efficacy perception as people's belief about their ability to produce a certain level of performance, influencing the various events in their lives and how they feel, think, motivate and behave. According to the Social Cognitive Theory (SCT), the development of self-efficacy includes cognitive, motivational, affective and selective processes based on the interpretation of information from four main sources: mastery experience, vicarious experience, social persuasions, and somatic/emotional states ${ }^{1}$.

The mastery experience is composed of the behavior experience followed by the interpretation of result, which is cognitively processed and is influenced by previous experiences ${ }^{2}$. It constitutes the most effective way to build a sense of self-efficacy, considering the success experienced from a challenging experience, with the overcoming of obstacles through effort and perseverance ${ }^{1}$.

The vicarious experience occurs from social models and is the interpretation of results obtained by observing other people performing a certain $\operatorname{task}^{1}$. It becomes important when the individual has doubts about his/her ability to perform the task, little previous experience and when the observer identifies with and/or admires the model observed ${ }^{2}$. The effect on the selfefficacy belief occurs when the model is successful in its performance ${ }^{1,2}$.

Social persuasion includes the encouragement or judgment of other people about the individual's ability, and to be effective, it must occur with reachable goals ${ }^{2}$. It can mobilize greater effort and persistence in the face of doubts or difficulties that arise during performance ${ }^{1}$.

Somatic and emotional states such as anxiety, stress, excitation, mood states, pain, tension, fatigue, can influence confidence, being interpreted as signs of vulnerability to poor performance ${ }^{1}$. Negative thoughts and fears about one's abilities can affect beliefs and generate limited behaviors ${ }^{1,2}$. To increase self-efficacy beliefs, there must be intervention in order to reduce stress reactions and negative thoughts, promote emotional well-being by helping regulate the physiological state in the face of new challenges ${ }^{1,2}$.

Studies on motor learning have confirmed the superiority of strategies with active participation of individuals through cognitive control over the environment conditions in which learning takes place 3 . Studies on motor learning with theoretical framework associated with SCT and its self-regulation and self-efficacy constructs have been called self-controlled learning, which refers to the practice condition that gives the learner control over one of the factors that affect the acquisition of motor skills, traditionally manipulated by the experimenter (demonstration, goal setting, practice structure and feedback - knowledge of results and performance) or other variables such as the use of physical assistance and the amount of practice ${ }^{4}$. Bandura's theory ${ }^{1,5}$ considers that such means act as inducers of strong self-efficacy and persistent and resilient behavior, when they culminate in successful experience.

The intervention on the individual's self-efficacy perception and other 
self-regulatory skills seems to be little explored, especially when associated with the motor learning process of children. This factor encouraged the conduction of this study, which aimed to verify the effect of intervention programs and / or methodologies based on SCT, with emphasis on selfefficacy, on the motor activity of children through the systematic review of randomized controlled clinical trials. 'Motor activity' was used in this review as a general term regarding variables on which the effects of different studies were analyzed, since some studies measure aspects of motor performance or motor learning and some physical activity. This term is therefore being used only when reference is not made to a specific study, but to a set of studies.

The question to be answered with this review is: what is the effect of interventions based on the concept of self-efficacy on children's motor activity? It is hoped that the results can contribute to the identification and systematization of a set of data that can support the construction of a mastery context for the motor learning of children through efficient intervention programs or protocols.

\section{METHOD}

This is a systematic literature review developed based on the PRISMA recommendations ${ }^{6}$.

The literature search strategy included articles available in the Scopus, PsycInfo, EBSCO Host, Medline, Lilacs, PubMed, Science Direct, IBECS, Scielo and Cochrane Central databases until January 18, 2018.

The search terms were in English using the $\mathrm{MeSH}$ terms, with the replication of the final search strategy built in PubMed in all other databases. English was not an eligibility criterion; however, all articles found were in this language. The final strategy used was: ("self-efficacy"[All Fields] OR "self-regulation"[All Fields]) AND ("motor skills"[All Fields] OR "motor activity”[A1l Fields] OR "motor learning”[A11 Fields]) AND ((“child”[MeSH Terms] OR "child”[All Fields]) OR ("child”[MeSH Terms] OR "child”[All Fields] OR "children"[All Fields])) AND ((“methods"[MeSH Terms] OR "methods”[All Fields] OR “intervention”[All Fields]) OR ("clinical trial”[Publication Type] OR "clinical trials as topic"[MeSH Terms] OR "clinical trial”[All Fields]) OR ("randomized controlled trial"[Publication Type] OR "randomized controlled trials as topic"[MeSH Terms] OR "randomized controlled trial"[All Fields] OR "randomized controlled trial”[All Fields])).

This review included randomized controlled clinical trials using the following criteria: (1) studies related to self-efficacy and motor skills of children aged 0-12 years; (2) studies aimed at analyzing, in some way, the study outcome in the light of the self-efficacy construct. Data collected are in the public domain and available in online databases. The ethical aspects were carefully observed, mainly in relation to data accuracy, respecting individual and collective authorship and the reliability of information 
presented in original texts.

The participation of different and independent reviewers was possible at the time of the construction of the search strategy (author and librarian), and in the analysis of study bias (three researchers). Disagreements were discussed for consensus.

To assess the risk of bias, the Cochrane Risk of Bias Tool ${ }^{7}$ was used, both for each clinical trial and to assess the quality of evidence on a given category of studies. This instrument assesses the risk of bias in the selection (generation of the randomization sequence and concealment of allocation), performance (blinding of the allocation for participants and research team), detection (blinding in the evaluation of results), attrition (incomplete reporting of results), description of results (selection of information), in a total of 6 domains. Classification is performed in low, undefined or high risk of bias, both for individual classification of clinical trials and for the quality of evidence about clinical trials on a given subject, considering the impact of these errors on the results of the study.

The characterization of studies followed the PICO reference: population / sample, intervention, comparison groups and outcomes. For each study, there was discrimination of variables analyzed and measurement instruments. For the analysis of results, the effects on motor activity and self-efficacy were considered, with description of the significance probability through the $\mathrm{p}$-value ${ }^{6}$.

Until January 18, 2018, 481 studies were found. Initial exclusions were related to duplicate, non-experimental studies and age of participants over 12 years. After reading titles and abstracts, studies related to self-efficacy that did not include the measurement of effects on motor activity were excluded. After the full reading of 23 articles, quasi-experimental studies, study protocols, research related to other concepts such as anxiety, selfconcept, attitudes and other emotions were excluded, as well as one study aimed at children with learning difficulties that measured the result on ocular and non-bodily motricity. As final sample, 16 clinical trials were descriptively analyzed in this systematic review.

\section{RESULTS}

Box 1 presents the results of each intervention model and the analysis of the risk of bias for each clinical trial, being categorized between studies with positive and non-positive effects on motor activity and self-efficacy.

Articles were published between 1991 and 2016. Fourteen studies evaluated children with typical development. Chen et al. ${ }^{8}$ investigated overweight children and Weiss et al. ${ }^{9}$ analyzed children with low confidence or fear of swimming. Twelve of the sixteen studies used the pre- and postintervention evaluation method, and only one study performed evaluation during the protocol application ${ }^{10}$. Regarding the evaluation of the longitudinal effect on the child's self-efficacy and motor activity (follow-up), Chen et $a .^{8}$ analyzed the effect of the weight gain prevention program on 
children 6 and 8 weeks after the end of intervention. Clark and Ste Marie ${ }^{11}$ and Weiss et al. ${ }^{9}$ performed follow-up 24 hours and 4 days after the end of the training program, respectively, as a retention phase of the trained motor skill. Therefore, there was limited number of studies with follow-up.

The total sample of trials was 5,511 , ranging from $17^{9}$ to $1,418^{12}$ participants.

Box 1. Effects of intervention models and analysis of the risk of bias in each clinical trial.

\begin{tabular}{|c|c|c|}
\hline Intervention Model & Intervention Model Results on motor self-efficacy and on the motor / physical component & $\begin{array}{l}\text { Bias } \\
\text { analisys }\end{array}$ \\
\hline & Studies with positive effects on self-efficacy and motor activity & \\
\hline CHAMP $^{13}$ & $\begin{array}{l}\text { Children in the CHAMP group demonstrated significant improvement in motor skills, both } \\
\text { in the total score and in dimensions locomotion and object control }(p<0.001) \text {. Children in } \\
\text { the control group decreased the time of the bonus test in the final evaluation, which did } \\
\text { not occur in the intervention group }(p<0.05) \text {. }\end{array}$ & High \\
\hline Youth Fit 4 Life $^{14}$ & $\begin{array}{l}\text { Increase in moderate to intense physical activity outside of school }(p<.001) \text {, self-regula- } \\
\text { tion for physical activity }(p<.001) \text {, self-efficacy for exercise }(p=0.015) \text { and negative mood } \\
(p=0.001) \text {. Physical activity mediated both changes in self-regulation and changes in } \\
\text { self-regulation mediated physical activity }(p<0.001) \text {, revealing reciprocity. }\end{array}$ & Undefined \\
\hline $\begin{array}{l}\text { Virtual animals at YPAP } \\
15\end{array}$ & $\begin{array}{l}\text { Children who interacted with the virtual animal showed higher self-efficacy level }(p<0.05) \\
\text { and greater amount of physical activity }(p=0.001) \text {. Self-efficacy had direct effect on be- } \\
\text { liefs }(p<0.01) \text { and the intention of future adherence to physical activity }(p<0.05) \text {. Beliefs } \\
\text { were predictors of greater self-efficacy }(p=0.001) \text {. }\end{array}$ & High \\
\hline $\begin{array}{l}\text { Original Youth Fit For } \\
\text { Life original (YFFL) and } \\
\text { revised (YF4L) })^{16}\end{array}$ & $\begin{array}{l}\text { Significant increase in time in moderate to vigorous physical activity in the intervention } \\
\text { groups compared to control }(p<0.001) \text { in males, being higher in the revised YF4L group. }\end{array}$ & Low \\
\hline $\begin{array}{l}\text { Exergame associated } \\
\text { with health education } \\
\text { messages }{ }^{17}\end{array}$ & $\begin{array}{l}\text { Effect of negative health education messages between the physical activity group with } \\
\text { Wii and without Wii on attitude }(p<0.001) \text {, self-efficacy }(p<0.01) \text { and perceived behavior } \\
\text { control }(p<0.05) \text {.Effects of coping health education messages in relation to negative mes- } \\
\text { sages for children in the control group (without Wii) on attitude }(p<0.01) \text {, self-efficacy ( } p \\
<0.05) \text { and perceived behavior control }(p<0.05) \text {. }\end{array}$ & High \\
\hline Start For Life ${ }^{18}$ & $\begin{array}{l}\text { Significant increase in time spent on vigorous physical activities }(p<0.001) \text { and from } \\
\text { moderate to vigorous }(p<0.05) \text {. }\end{array}$ & Undefined \\
\hline $\mathrm{HEI}^{10}$ & $\begin{array}{l}\text { There was an increase in self-efficacy after } 8 \text { months of intervention only in children with } \\
\text { normal weight }(p=0.01) \text {. Reduction of self-efficacy in the intervention group }(p=0.02) \text {. } \\
\text { Children who reported low doses of the intervention had increased self-efficacy in the final } \\
\text { measure }(p=0.001) \text {. }\end{array}$ & Undefined \\
\hline SIRKS $^{12}$ & $\begin{array}{l}\text { Improvement in the knowledge of the amount of physical activity required }(p<0.001) \text { and } \\
\text { the benefits of physical activity }(p<0.01) \text {, expectations of results for physical activity }(p \\
<0.05) \text {, in self-efficacy to seek support performance of physical activity }(p=0.04) \text {. There } \\
\text { was no difference in self-efficacy to overcome barriers to physical activity }(p=0.30) \text {. }\end{array}$ & High \\
\hline Switch Off-Get Active ${ }^{19}$ & $\begin{array}{l}\text { There was a significant increase in the time of involvement in moderate to vigorous physical ac- } \\
\text { tivity }(p=0.03) \text { and in the self-efficacy for physical activity in the intervention group }(p=0.03) \text {. }\end{array}$ & Undefined \\
\hline $\begin{array}{l}\text { Peer modeling - peer- } \\
\text { coping peer-mastery } \\
\text { (video) }\end{array}$ & $\begin{array}{l}\text { Peer modeling increased self-efficacy in swimming }(p<0.01 \text {; post-intervention and follow- } \\
\text { up). Fear of swimming decreased in both modeling groups, with greater effect than in the } \\
\text { control group. The coping pair modeling group prevailed in improving the ability to swim, } \\
\text { in self-efficacy and in decreasing fear of swimming }{ }^{* *} \text {. }\end{array}$ & Undefined \\
\hline $\begin{array}{l}\text { Peer and teacher } \\
\text { modeling } 20 \\
\text { (video) }\end{array}$ & $\begin{array}{l}\text { The modeling groups performed significantly better than the control group }(p<0.009) \text {. At } \\
\text { follow-up, the number of steps and execution was higher than in the control group }(p<0.01) \text {. } \\
\text { The skilled model was more efficient both for number of steps }(p<0.01) \text { and for execution } \\
(p<0.001) \text { and between attempts }(p<0.01) \text {. The interest of the skilled modeling group in } \\
\text { comparing their performance to that of the model was significant }(p<0.04) \text {. Self-efficacy } \\
\text { increased only after skilled modeling }(p<0.001) \text {. In the questionnaire applied after watching } \\
\text { the modeling video, the non-skilled model group had less self-efficacy than the control and } \\
\text { the skilled model group ( } p<0.05) \text {. After performing the task, the skilled modeling group } \\
\text { had greater increase in self-efficacy ( } p<0.05) \text {. Compared to the control group, self-efficacy } \\
\text { decreased during the attempts in both skilled and unskilled modeling groups }(p<0.05) \text {. }\end{array}$ & Undefined \\
\hline
\end{tabular}

Continue... 
... continue

\begin{tabular}{|c|c|c|}
\hline Intervention Model & Intervention Model Results on motor self-efficacy and on the motor / physical component & $\begin{array}{l}\text { Bias } \\
\text { analisys }\end{array}$ \\
\hline JUMP-in ${ }^{21}$ & $\begin{array}{l}\text { Increased participation in sport in the intervention group }(p<0.001) \text {. The intervention } \\
\text { group had significantly less self-efficacy than the control in baseline measurements }(p \\
<0.05) \text {. After intervention, there was a positive and significant correlation between self- } \\
\text { efficacy and participation in sport and frequency of outdoor activities }(p=0.001) \text {. }\end{array}$ & High \\
\hline Self-as-a-model ${ }^{11}$ & $\begin{array}{l}\text { Physical performance improved throughout sessions }(p=0.001) \text {, with greater effect on } \\
\text { the self-modeling group }(p=0.002) \text {, including in the retention period }(p=0.001) \text {. Self-ef- } \\
\text { ficacy increased over the sessions }(p=0.01) \text {, but was not statistically significant between } \\
\text { groups }(p=0.03) \text {. Only in the retention phase, significantly higher intrinsic motivation and } \\
\text { self-satisfaction in the self-modeling group was identified }(p=0.001) \text {. }\end{array}$ & Undefined \\
\hline \multicolumn{3}{|c|}{ Studies with non-positive effects on self-efficacy or motor activity } \\
\hline$A B C^{8}$ & $\begin{array}{l}\text { There was a decrease in BMI }(p=0.001) \text { and diastolic blood pressure }(p=0.03) \text {, with } \\
\text { increase in the amount of physical activity }(p=0001) \text { and knowledge about physical activ- } \\
\text { ity }(p=0.02) \text {. }\end{array}$ & Undefined \\
\hline JUMP-in ${ }^{22}$ & $\begin{array}{l}\text { Intervention group demonstrated greater perception of advantages over physical activity } \\
(p<0.05) \text { and habitual practice of physical activity }(p<0.05) \text {. Reduced physical activity } \\
\text { time in the intervention group }(p<0.001) \text {. }\end{array}$ & High \\
\hline IMPACT $^{23}$ & $\begin{array}{l}\text { Reduction in the percentage of time in physical activity from moderate to vigorous in boys } \\
(p=0.02) \text {, reduction in the percentage of time for boys in light physical activity, increase in } \\
\text { time for girls in light physical activity }(p=0.052) \text {. Improvement in the outcome expecta- } \\
\text { tions in boys }(p<0.027) \text {. }\end{array}$ & High \\
\hline
\end{tabular}

* distribution by groups was not informed. ${ }^{* *}$ the Effect Size was calculated and not the $p$-value.

The duration of intervention varied between a single session ${ }^{20}$ and 20 months $^{10}$, with the most common being 8 weeks ${ }^{9,12,18,23}$. Intervention sessions took place over 3 times a week in most studies ${ }^{13,14,16,18}$. In 6 studies $^{10,12,19,21-23}$ the weekly frequency was not controlled because the intervention program was applied by teachers in the school routine.

In three studies, no procedure was performed with the control group $^{12,19,22}$. In all others, control groups underwent modified intervention or remained in the school exercise routine.

Most studies used the abbreviation of questionnaires, questions present in more than one questionnaire or questions elaborated by the authors for application in that research, especially in the self-efficacy evaluation. Although the authors present the psychometric reliability of their instruments, it is important to highlight the reduced number of items that proposed to assess self-efficacy or self-regulation in questionnaires, ranging from thre $\mathrm{e}^{15,17}$ to 12 items ${ }^{22}$. The questionnaire to measure psychosocial influences on physical activity in children by Saunders et al. ${ }^{24}$ was the only one that was present in more than one study ${ }^{19,23}$.

Fourteen different intervention models were described, 11 of which were built using the TSC theoretical framework, seeking to identify the effect of programs on preventing weight gain and physical inactivity among children (Exergame, IMPACT, Start for Life, ABC, YFFL, SIRKS, Switch off-Get Active, virtual animals in YPAP), and the effect of the modeling strategy on the teaching of motor skills (self-modeling, peer and teacher modeling, and modeling by skilled peers and unskilled peers). The other 3 intervention models, based on other theoretical references, focused on assessing the effects on self-efficacy and motor activity 
or used an instrument to assess the child's motor performance (JUMP-in, CHAMP, HEIA).

According to Higgins ${ }^{7}$, the quality of evidence of studies with positive effect on self-efficacy and motor activity is undefined, since most of its evidence comes from clinical trials with low risk or undefined bias (8 of 13 studies; 61\%). The quality of evidence of studies with non-positive effect on self-efficacy and motor activity is of high risk, since clinical trials mostly presented high-risk bias (2 of 3 trials; 67\%).

Box 2 presents the strategies used by intervention models chosen among the four sources of self-efficacy.

Box 2. Categorization of the characteristics of intervention models within the sources of self-efficacy.

\begin{tabular}{|c|c|}
\hline $\begin{array}{l}\text { SOURCES OF } \\
\text { SELF-EFFICACY }\end{array}$ & STRATEGIES USED IN INTERVENTIVE MODELS \\
\hline Direct Experience & $\begin{array}{l}\text { Subjective experience lived in the practice of motor activity: } \\
\text { - the virtual game (Wii game) with the child's choice of three different goals for fitness; } \\
\text { - related to the motor task chosen as the goal; } \\
\text { - vigorous physical exercises alternated with light intensity exercises, muscle strength and endurance } \\
\text { training, cardiovascular training, non-competitive and sports activities. } \\
\text { Held at a specific time in the program, during class breaks or during the week with accelerometer } \\
\text { monitoring. } \\
\text { Self-monitoring increased intensity, progress in activity, training objectives or barriers to changes in } \\
\text { behavior } \\
\text { Self-reflection from performance }\end{array}$ \\
\hline Vicarious Experience & $\begin{array}{l}\text { Group activities with consequent modeling by peers; modeling with the choice of people that consider } \\
\text { important for their evolution within their purpose or learning experience; video self-modeling (better } \\
\text { performance - removing errors) and video self-observation (without removing errors). } \\
\text { Demonstration and development of instruction and self-instruction of the critical elements of motor } \\
\text { activity. }\end{array}$ \\
\hline Social Persuasion & $\begin{array}{l}\text { Short and long term goals; interconnected goals; } \\
\text { Information for developing decision-making and self-control skills } \\
\text { Information for developing self-esteem and self-concept } \\
\text { Individualized performance feedback and encouragement; } \\
\text { Emphasis on competition with oneself; } \\
\text { Information on the importance of these behavioral strategies for health, the importance of physical } \\
\text { activity and dangers of inactivity, and on short and long-term results of behavior change, through } \\
\text { Multichannel, CD-ROOMS, lessons, printed material. } \\
\text { Social support with material for parents, other family members, teachers and friends; } \\
\text { Support from community with teaching street games, in parks and physical activity in the community } \\
\text { environment. } \\
\text { Rewards: use of cards with achieved goals, certificate of achieved goals, activity record diary, tickets, } \\
\text { representations by posters and graphics, prizes, entertainment and interactivity; }\end{array}$ \\
\hline $\begin{array}{l}\text { Somatic / Physiological } \\
\text { States }\end{array}$ & $\begin{array}{l}\text { Warm-up and cooling down activities; } \\
\text { Self-management of emotions and behaviors in social environments; } \\
\text { Stress reduction techniques: deep breaths, stretching, simple Yoga postures, relaxation and other } \\
\text { postural exercises. }\end{array}$ \\
\hline
\end{tabular}

\section{DISCUSSION}

The present review sought to systematize the results of intervention studies on the motor activity of children using protocols built from the self-efficacy theory and its sources of information. Described and analyzed studies show the importance of the self-efficacy construct, sometimes on learning or acquiring a motor skill, sometimes on motor performance and increased physical activity in this population. However, more rigorous methodologi- 
cal procedures should be carried out so that the results of these studies provide answers to this research question.

Eight studies reported significant positive effect of intervention on self-efficacy. These studies include Exergame programs associated with health education messages ${ }^{17}$, SIRKS ${ }^{12}$, YF4L ${ }^{14}$, Switch Off - Get Active $^{19}$, HEIA ${ }^{10}$, YPAP with virtual anima ${ }^{15}$ and two of the studies with modeling ${ }^{9,20}$. The CHAMP ${ }^{13}$ intervention model obtained a preventive response on self-regulation, which did not decrease in the intervention group as occurred in the control group. The JUMP-in ${ }^{21}$ protocol; however, did not cause significant changes in self-efficacy between control and intervention groups, but there was a positive and significant correlation among self-efficacy measures for participation in sport and outdoor activities, being considered a potential mediator. In the study by Clark and Ste-Marie ${ }^{11}$, although there was no difference in self-efficacy between groups and sessions, their measurements increased during sessions, and this increase was greater in the self-modeling group.

Annesi and Vaughn ${ }^{15}$ comparing the two versions of YFFL (YF4L) and Annesi et al. ${ }^{17}$ with Start For Life, and did not measure self-efficacy, but have both intervention models built in the light of TSC and with emphasis on self-efficacy. Its outcome on motor activity is quite significant. Considering the most objective measurement method (accelerometer), these data become important in the construction of evidence. In their 2016 study, Annesi et al. ${ }^{14}$ evaluated self-efficacy and self-regulation for physical activity using the same YF4L protocol as intervention, and presented very important results in both constructs.

In addition to performing objective assessments of the amount of physical activity using accelerometer ${ }^{15,16,18,23}$, Robinson et al. ${ }^{13}$ also used the Test of Gross Motor Development 2nd edition (TGMD-2) as a standardized instrument for assessing the child's motor skills. These standardized assessment methods are important in determining the methodological quality of the study and its results.

In modeling studies, the greater impact on learning motor skills from videos with skilled models or self-modeling (video of the best performance) is evident. As for self-efficacy improvement, it is not possible to define which type of modeling becomes more effective, considering the results of studies in which less skilled models had greater impact on self-efficacy ${ }^{9}$ and its decrease during swimming attempts in both skilled as not skilled modeling groups ${ }^{20}$.

Other variables related to self-efficacy for motor activity were tested in isolation, such as beliefs, attitudes, social persuasion, perception of barriers, outcome expectations, mood, motivation and satisfaction/pleasure. Only beliefs in the benefits of physical activity were predictors of greater self-efficacy ${ }^{15}$.

The categorization of the characteristics of intervention programs based on the four sources of self-efficacy reveals that only 6 of the 11 intervention models worked with all sources of self-efficacy. The greatest presence 
is of persuasion related to the establishment of goals and different forms of monitoring by the research team or the school; health information material and classes and physical activities; encouraging participation and information about social support from the family. The SIRKS protocol, for example, was composed only of this collective marketing resource. Despite the importance given by Bandura ${ }^{1,2,5}$ to the direct experience of success on what is being developed or acquired within the scope of these studies on motor activity in children, three of the intervention models ${ }^{18,19,23}$ did not offer the practice of physical activity, despite stimulating it.

Seven intervention models tested in 6 studies $^{10,13,14,16,18,21}$ revealed a positive effect on self-efficacy from the group intervention. In the present analysis, this aspect was considered as a factor of collective modeling and social persuasion among children. Bandura ${ }^{1}$ highlights the strength of the peer relationship in building the concept of self-efficacy among children. According to Bergh ${ }^{10}$, increased self-efficacy for physical activity was identified at follow-up only in children with normal weight. The authors suggest that social comparison between overweight children and normal weight children may have been negative for the self-efficacy of overweight children. Bandura ${ }^{1}$ points out that children are especially sensitive to their position among peers in activities that involve prestige or popularity.

Three ${ }^{8,22,23}$ studies did not obtain significant effects of intervention on self-efficacy, one of which obtained results in increasing the amount of physical activity among children ${ }^{8}$. These studies used Jump-in, IMPACT and $\mathrm{ABC}$ as intervention models. Despite the poor quality of evidence among studies, those who did not obtain results on self-efficacy were fewer and had higher risk of bias. In view of the potentiality of the self-efficacy construct on children's motor activity demonstrated through the various results, it is important to improve the methodological strategies used in studies in order to reach a scientific consensus on this evidence.

The appreciation of characteristics of studies and of intervention models does not show important differences that justify the positive effects or not on self-efficacy and motor activity, when analyzed in the light of the sources of self-efficacy. One of the explanatory possibilities may be the methodological rigor used. This review also makes an important contribution by discriminating the strategies used in intervention protocols according to the four sources of self-efficacy, which allows identifying practices of building a context of mastery, favorable to the establishment of an adequate concept of motor self-efficacy in children and development of their self-regulatory skills. The importance of knowledge about the subjectivity of these experiences is highlighted in order to build the self-efficacy of individuals who experience such practices.

\section{FINAL COMMENTS}

This systematic literature review shows that the concept of self-efficacy, when related to motor activity in children, has been applied more frequently 
in controlled and randomized experimental trials that use broad intervention programs, predominantly in the school environment, collectively, stimulating aspects related to children's health such as food and physical activity, and childhood obesity prevention.

The studies analyzed show important results in the development of self-efficacy and motor activity among children, but they are not conclusive regarding self-efficacy mediation in the performance of physical activity or motor skill acquisition.

As highlighted by Van-Stralen et al. ${ }^{21}$, either self-efficacy and / or selfregulation do not mediate the child's motor activity or they are not able to express it in questionnaires. It is also necessary to consider the small number of items evaluated by these mediators in the vast majority of studies, and the weak evidence produced so far, considering the analysis of risk of bias.

However, the interventions found in studies and detailed in this manuscript allow detecting strategies for building a context of mastery, theoretically favorable to the establishment of an adequate concept of self-efficacy in children, with greater control over their learning in order to generalize it.

Most studies focus on children with typical development. Little is known about the effects of such strategies related to self-efficacy on the learning of children with motor dysfunction in a context of rehabilitation, considering the importance of the perception of competence in these cases ${ }^{25}$ and their mediation in the participation of these children ${ }^{26}$.

From the academic-scientific point of view, it is expected that the results systematized and analyzed in the present review can stimulate the development of new investigations on self-efficacy in children, measurement methodologies for this construct and greater methodological rigor in the control of experimental variables. From the social point of view, considering that the exploration of knowledge in the practice of physical activity or the teaching of motor skills is still quite restricted to the research environment and little known by school and rehabilitation professionals, this review should contribute to practices of professionals who invest in the process of building the sense of self-efficacy, with a view to making children adults who believe in the benefits of physical activity.

\section{COMPLIANCE WITH ETHICAL STANDARDS}

\section{Funding}

This research was supported by CAPES.

\section{Ethical approval}

The article was written in accordance with standards set by the Declaration of Helsinki.

\section{Conflict of interest statement}

The authors have no conflict of interests to declare. 


\section{Author Contributions}

Conceived and designed experiments: SFO, CMSM. Performed experiments: SFO, MGM, MOF, CMSM. Analyzed data: SFO, MGM, MOF, CMSM. Contributed with reagents/materials/analysis tools: SFO, MGM, MOF, CMSM. Wrote the paper: SFO, MGM, MOF, CMSM.

\section{REFERENCES}

1. Bandura A. Self-efficacy. In: Ramachaudran V. (Ed.). Encyclopedia of human behavior. New York: Academic Press, 1994. p. 71-81.

2. Pajares F, Olaz F. Teoria social cognitiva e autoeficácia: uma visão geral. In: Bandura A, Azzi RG, Polydoro SA. Teoria Social Cognitiva: conceitos básicos. 1 Ed. São Paulo: Artmed Editora, 2008. p. 97-114.

3. Bruzi A, Bastos F. Efeito da demonstração autocontrolada na aprendizagem motora. In: Tani G. Comportamento Motor: conceitos, estudos e aplicações. 1 Ed. Rio de Janeiro: Guanabara Koogan, 2016. p. 89-96.

4. Walter C, Bastos FH, Araújo UO, Tani G. Estudo da Aprendizagem Motora Autocontrolada: Fundamentos e Perspectivas. In: Tani G. Comportamento Motor: conceitos, estudos e aplicações. Rio de Janeiro: Guanabara Koogan, 2016. p.17-23.

5. Bandura A. Self-efficacy: Toward a Unifying Theory of Behavioral Change. Psychol Rev 1977; 84(2): 191-215.

6. Moher D, Liberati A, Tetzlaff J, Altman DG, The PRISMA Group. Preferred Reporting Items for Systematic Reviews and Meta-Analyses: The PRISMA Statement. Plos Med 2009; 6(6): e1000097.

7. Higgins JPT, Altman DG, Gøtzsche PC, Jüni P, Moher D, Oxman AD, et al. The Cochrane Collaboration's tool for assessing risk of bias in randomised trials. BMJ 2011; 343:d5928.

8. Chen JL, Weiss S, Heyman MB, Lustig RH. Efficacy of a child-centred and family-based program in promoting healthy weight and healthy behaviors in Chinese American children: a randomized controlled study. J Public Health 2009; 32(2):219-229.

9. Weiss MR, Mccullagh P, Smith AL, Berlant AR. Observational Learning and the Fearful Child: Influence of Peer Models on Swimming Skill Performance and Psychological Responses. Res QExerc Sport 1998; 69(4):380-394.

10. Bergh IH, Bjelland M, Grydeland M, Lien N, Andersen LF, Klepp KI, et al. Midway and post-intervention effects on potential determinants of physical activity and sedentary behavior, results of the HEIA study - a multi-component school-based randomized trial. Int J Behav Nutr Phys Act 2012; 9:63.

11. Clark S, Ste-Marie D. The impact of self-as-a-model interventions on children's self-regulation of learning and swimming performance. J Sports Sci 2007; 25(5):577-586.

12. Keihner AJ, Meigs R, Sugerman S, Backman D, Garbolino T, Mitchell P. The Power Play! Campaign's School Idea \& Resource Kits Improve Determinants of Fruit and Vegetable Intake and Physical Activity among Fourth- and Fifth-Grade Children. J Nutr Educ Behav 2011; 43(4):S122-S129.

13. Robinson L, Palmer K, Bub K. Effect of the Children's Health Activity Motor Program on Motor Skills and Self-Regulation in Head Start Preschoolers: An Efficacy Trial. Front Public Health 2016; 4:1-9.

14. Annesi J, Walsh S, Greenwood B. Increasing Children's Voluntary Physical Activity Outside of School Hours Through Targeting Social Cognitive Theory Variables. J Prim Care Community Health 2016; 7(4):234-241.

15. Ahn SJ, Johnsen K, Robertson T, Moore J, Brown S, Marable A, et al. Using Virtual Pets to Promote Physical Activity in Children: An Application of the Youth Physical Activity Promotion Model. J Health Commun 2015; 20(7):807-815. 
16. Annesi J, Vaughn L. Evidence-Based Referral: Effects of the Revised "Youth Fit 4 Life” Protocol on Physical Activity Outputs. Perm J 2015; 19(3):48-53.

17. Lwin MO, Malik S. Can Exergames Impart Health Messages? Game Play, Framing, and Drivers of Physical Activity Among Children. J Health Commun 2014; 19:136-151.

18. Annesi J, Smith A, Tennant G. Effects of the Start For Life treatment on physical activity in primarily African American preschool children of ages 3-5 years. Psychol Health Med 2013; 18(3):300-309.

19. Harrison M, Burns CF, Mcguinness M, Heslin J, Murphy NM. Influence of a health education intervention on physical activity and screen time in primary school children: 'Switch Off_-Get Active'. J Sci Med Sport 2006; 9:388-394.

20. Lirgg C, Feltz D. Teacher versus Peer Models Revisited: Effects on Motor Performance and Self-Efficacy. Res QExerc Sport 1991; 62(2):217-224.

21. Van Stralen MM, Meij J, Velde SJ, Van Der Wal MF, Mechelen W, Knol DL, et al. Mediators of the effect of the JUMP-in intervention on physical activity and sedentary behavior in Dutch primary schoolchildren from disadvantaged neighborhoods. Int J Behav Nutr Phys Act 2012, 9:1:131.

22. Jurg ME, Kremers SPJ, Candel MJJM, Van Der Wal MF, Meij JSB. A controlled trial of a school-based environmental intervention to improve physical activity in Dutch children:JUMP-in, kids in motion. Health Promot Int 2006; 21(4):320-330.

23. Goran M, Reynolds K. Interactive Multimedia for Promoting Physical Activity (IMPACT) in Children. Obes Res 2005; 13(4):762-771.

24. Saunders RP, Pate RR, Felton G, Dowda M, Weinrich MC, Ward DS, et al. Development of Questionnaires to Measure Psychosocial Influences on Children's Physical Activity. Prev Med 1997; 26(PM960134241):241-247.

25. Engel-Yeger B, Weissman D. A comparison of motor abilities and perceived selfefficacy between children with hearing impairments and normal hearing children. Disabil Rehabil 2009; 31(5):352-8.

26. Rosenberg L, Jarus T, Bart O, Ratzon NZ. Can personal and environmental factors explain dimensions of child participation? Child Care Health Dev 2010; 37(2):266-275.

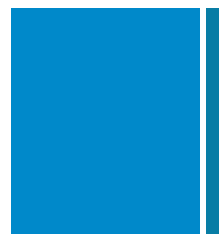

Corresponding author

Sabrina Ferreira de Oliveira

Universidade Federal do Triângulo Mineiro.

Núcleo de Assistência Estudantil em Saúde.

Getúlio Guaritá, 440. Abadia. 38025-440

Uberaba, MG - Brasil.

Email: sassafisio@hotmail.com 